\title{
Lúcia / Miguel: romance e crítica
}

\author{
Luiz Roncari
}

RESUMO: O estudo tem em vista mostrar como Lúcia Miguel Pereira procurou reunir num trabalho de criação os resultados da pesquisa e da crítica literária. Como se dedicou seriamente a essas diferentes atividades e tinha muita consciência de suas diferenças, tal fato pode ter-lhe trazido ganhos e perdas. Para tanto, este ensaio investiga a hipótese de ela ter se aproveitado da novela Casa Velha, de Machado de Assis, - cujo resgate e publicação em livro se deveu a ela própria — na construção de seu último romance, Cabra-Cega.

PALAVRAS-CHAVE: Lúcia Miguel Pereira; Machado de Assis; Casa Velha; Cabra-Cega.

ABSTRACT: This study aims to show how Lucia Miguel Pereira tried to gather in a creative work the results of her research and literary criticism. As she was seriously devoted to these different activities and was very aware of their differences, this fact may have brought him gains and losses. To this end, this paper investigates the hypothesis that she had taken advantage of the novel Machado de Assis ' Casa Velha - whose rescue and publication in book form was due to her own - in the construction of his latest novel, Cabra-Cega.

KEYWORDS: Lúcia Miguel Pereira; Machado de Assis; Casa Velha; Cabra-Cega. 
Já nos acostumamos a dizer que foi no período dos anos 30 ao final dos 60 que tivemos a nossa melhor poesia, nosso melhor romance e ensaio interpretativo do Brasil. Mas creio que poderemos dizer também que foi o de nossa melhor crítica literária, ao menos no sentido mais comum do termo, de intermediária importante entre o autor e o leitor. Ela, nesse tempo, além do julgamento das obras, tinha em vista também a formação e o desenvolvimento de ambos: de corrigir os descaminhos, apontar as carências e reprovar os excessos dos autores; e estimular a leitura e fornecer as mediações necessárias aos leitores. Ao mesmo tempo, a melhor crítica aprendia também com eles, esforçava-se tanto para entender os primeiros como para ser entendida pelos segundos. Lúcia Miguel Pereira foi uma digna representante dessa crítica, formada antes de tudo por homens cultos e amantes da literatura, que se sentiam imbuídos também de uma missão ética e formativa. ${ }^{1}$ Depois, a partir dos anos 70, essa espécie de crítica literária minguou e o que a substituiu foram, grosso modo, por um lado, as resenhas jornalísticas pouco cuidadas e com finalidades mais propagandísticas e, por outro, os estudos acadêmicos densos e feitos por e para especialistas. Com isso, perdeu-se em boa parte o diálogo que havia entre os três atores: autor, crítico e leitor; infelizmente, penso eu, e para prejuízo de todos.

O título do trabalho, "Lúcia / Miguel: romance e crítica", eu o pensei a partir de um pequeno artigo de Antonio Candido a propósito do lançamento do primeiro volume de reunião de crítica da autora: A leitora e seus personagens, organizado por Luciana Viégas e prefaciado por Bernardo de Mendonça. Candido ressalta como foi constante nela a preocupação com "o problema feminino", desde os seus primeiros artigos publicados - de 1927, para uma revista que também dirigiu, Elo: Revista das "Antigas" de Sion -, até o trágico desastre aéreo que sofreu, deixando inacabado um trabalho sobre o tema. Diz o crítico:

Mas, seja como for, serve para mostrar como foi precoce o interesse por um dos temas centrais de sua reflexão, valendo a pena mencionar que quando morreu estava preparan-

1. Antonio Candido, que também fez parte desse grupo, numa entrevista, em 1979, deixou claro esse espírito "participante" da crítica do tempo: "Produzir um rodapé por semana é muito duro; e, como disse, não teria mais o mesmo sentido, porque passou o tempo do tijolo de 6 e 7 colunas onde aliás se estudava a obra a sério, contribuindo para formar a opinião literária. Hoje os métodos são outros". In: Brigada ligeira e outros escritos. São Paulo: Editora Unesp, 1992, p. 245. 
do, com o afinco e a probidade que punha em todos os seus trabalhos, um livro alentado sobre a condição feminina no Brasil, em perspectiva histórica. ${ }^{2}$

A esse artigo, Candido deu mais do que um título, deu-lhe um nome, assim singelo, mas reluzente, como a lembrar a sua etimologia: "Lúcia". Não sei se foi para evocar também a sua pessoa ou falar da proximidade e da amizade ou possivelmente parentesco que teria com ela - a mãe da autora, Maria Clara, tinha também o sobrenome Tolentino, como a mãe do crítico, Clarisse Tolentino de Mello e Souza. Acrescentei ao título de meu trabalho o "Miguel", para introduzir o tema, que só em parte desenvolverei nele, que é o da "androginia" da autora - androginia intelectual, bem entendido. Foi ela própria que, num dentre os vários artigos que escreveu sobre Virgínia Woolf, discorreu sobre a dualidade da escritora inglesa, enquanto romancista e ensaísta: "inquieta por se sentir, intelectualmente, andrógina, fadada a pensar ora como homem, ora como mulher" (grifo meu). Segundo Lúcia, essas atividades requeriam aptidões distintas, que poderiam ser próprias de cada um dos sexos. Ela fala:

Dizem - estará mesmo certo? - que o espírito racionalista pertence mais aos homens, e a sensibilidade às mulheres. Virgínia possuiu um e outra no mais alto grau, mas não os confundiu: com aquele fez crítica, com esta romances. Toda graça, às vezes até um pouco maneirosa, toda suavidade e meiguice se mostra nas novelas; toda clareza, ousadia e penetração, aparece nos ensaios.

E ela disserta como Virgínia representou e explorou esse tema da androginia no seu romance biográfico, Orlando, que, de certo modo, seria também autobiográfico: "Orlando é Virgínia Woolf; ou melhor, representa certos aspectos, certas características do espírito de Virgínia Woolf”. E diz como a escritora inglesa também não se tolhia: compreendia e aceitava a dualidade, integrava em si a dimensão masculina e feminina e não aceitava a divisão rígida entre os sexos. Diz Lúcia:

Orlando, que depois da metamorfose reunia as tendências psicológicas do rapaz que fora e da moça que era, pensava que "negar mas ceder é delicioso" (lado feminino): "perseguir e conquistar é admirável"; "perceber e raciocinar é sublime" (lado masculino). E Virgínia

2. Candido, Antonio. O Albatroz e o Chinês. Rio de Janeiro: Ouro sobre Azul, 2004, p. 129. 
explica que, embora nenhum desses pares de palavras lhe parecesse errado, ela se sentia culpada, desonrada, porque os agregava uns aos outros, porque compreendia a todos, pois isso tornava patente que não distinguia claramente a linha que divide os sexos. ${ }^{3}$

Numa outra crítica, ainda sobre Virginia Woolf, Lúcia mostra como era também, segundo parece, com esse metro da androginia, da integração ou do predomínio do masculino e do feminino, dependendo da disposição intrínseca de cada um, que ela considerava e dividia os escritores. Isto ela faz numa crítica ao fascismo e a Mussolini, que Lúcia comenta:

Mas, no fascismo, não foi a opressão que unicamente a horrorizou; achou intolerável em Roma o ambiente criado por Mussolini, de predomínio exclusivo dos homens, de confinação das mulheres às atividades estritamente domésticas. Aquela masculinidade inflexível, "unmitigated masculinity" lhe pareceu desastrosa para a literatura porque aqui reaparece feminista - sem a colaboração de ambos os sexos, a arte seria inviável, uma espécie de monstro fabricado artificialmente. Não a colaboração no sentido apenas de ambos poderem livremente escrever, mas noutro, de ordem psicológica; na aceitação, pelos homens, do espírito feminino, e pelas mulheres, do masculino. Toda a sua argumentação neste livro se baseia no androginismo dos criadores. Shakespeare era, segundo ela, andrógino, e também Keats, Sterne, Cowper, Lamb e Coleridge; já Milton e Bem Johnson eram mais masculinos, assim como Wordsworth e Tolstoi; Proust lhe parece mais feminino, e Shelley, coitado, assexuado. ${ }^{4}$

O que procurarei mostrar aqui, por um lado, é como Lúcia reuniu num mesmo trabalho de criação o feminino e o masculino, ao integrar nele os frutos da pesquisa e da leitura crítica; e, por outro, a partir da apreciação de seus resultados, verei como isso pode ser também problemático. Desse modo, em vez de falar da crítica e da criação literária de Lúcia Miguel Pereira em geral, preferi tomar um caso particular e, a partir de sua análise, verificar como ela tentou casar essas duas atividades.

3. Pereira, Lúcia Miguel. Escritos da maturidade. Rio de Janeiro: Graphia Editorial, 1994, p. 94.

4. Id., pp. 99 e 100. 


\section{DA CASA VELHA À CABRA-CEGA}

O trabalho em questão é o seu último romance, Cabra-Cega. Nele, Lúcia explora as tensões - e, para isso, se aproveita de sua experiência - da relação entre espaço e tempo, o que está no núcleo mesmo do livro. Para mim, e é esta a hipótese, o que deve tê-lo sugerido e a ajudou a pensá-lo e construí-lo foi um outro romance, de Machado de Assis, Casa Velha.

Segundo John Gledson, baseado no prefácio escrito por Lúcia para a edição em livro de Casa Velha, em 1944, devemos a ela o resgate e a reedição desse folhetim publicado por Machado de Assis na revista carioca A Estação, de 1885 a 1886: "devemos nosso conhecimento da obra, na verdade, a sua paciência e perseverança na busca dos números perdidos da revista". ${ }^{5}$ Ela mesma se refere ao trabalho que teve para fazer esse resgate. Casa Velha é um livro que levanta muitas discussões, tanto acerca de seu gênero, se é conto, novela ou romance, como do período em que foi escrito; ele destoa muito dos romances do autor do tempo da publicação do folhetim e apresenta pontos comuns com os considerados da primeira fase, ou seja, os anteriores ao Brás Cubas. Não poderei de modo nenhum entrar nessas discussões. ${ }^{6}$ Só irei ressaltar os pontos que, para mim, teriam sido importantes para Lúcia reproduzi-lo num outro tempo, quando escreveu Cabra-Cega, publicado em 1954. A comparação mais detida entre essas duas obras, explorando as diferentes perspectivas históricas, poderia nos trazer uma contribuição boa sobre os livros dos dois autores.

Em síntese, para mim, Machado procurou nesse livro retratar na sua totalidade as principais relações sociais vividas no país, só que agora isoladas no microcosmo de uma Casa Grande, como se faz nos laboratórios para a observação do comportamento animal e no teatro burguês para a dos humanos. Aí ele pôde apreciar a vida e o fun-

5. Gledson, John. Machado de Assis: ficção e história. Tradução de Sônia Coutinho. São Paulo: Paz e Terra, 1986, p. 26.

6. Concordo muito com o que diz Gledson, que considera Casa Velha uma espécie de elo perdido entre os romances da primeira fase, Helena e Iaiá Garcia, e o da segunda, Dom Casmurro: “Já mencionei importantes paralelismos entre suas tramas e a de Casa Velha; parece mais provável que nossa história seja um elo perdido entre essas primeiras (e falhas) meditações sobre o sistema do favor, e o brilho e complexidade de Dom Casmurro. Como já sugerimos, Casa Velha reduz à sua forma essencial o tema comum a ele e aos dois romances anteriores; constitui-se, de fato, um ataque muito mais direto à raiz de todo o mal, a família patriarcal de classe superior”. Gledson, John. Op. cit., pp. 53 e 54. 
cionamento de uma família patriarcal, extensa e com as suas duas faces imbricadas: a privada, do idílio familiar, e a pública, do poder de favores e violência social e política. Creio que seja daí que venha a sua grande força alegórica. Gledson nota bem esse aspecto da narrativa no seu estudo pioneiro. Ele diz:

A alegoria política/histórica é apenas uma possível dimensão do significado presente na trama. [...] Casa Velha é um drama de família, mas que Machado utilizou com o objetivo claro de refletir realidades sociais, e também políticas, mais amplas - na verdade, como demonstrei, os acontecimentos políticos em si parecem ser reproduzidos pelas necessidades e limitações de um certo tipo de sociedade. ${ }^{7}$

Sem dúvida, o ..do significado presente na trama. vada e p esse resgate. que se passa em seu interior tem uma significação mais ampla e pode ser estendida ao país. Gledson se detém no desvendamento das referências políticas e simbólicas, sem se preocupar tanto, ao que me parece, com os elementos propriamente estruturais, os que conformavam a sociedade brasileira de então. Isto é importante, pois, do meu ponto de vista, e o título chama para isso, o foco do autor estava mais no que permanecia do que no que mudava; em outros termos, naquilo que, quanto mais velho ficava, o tempo, em vez de renovar, reafirmava. Para mim, Machado visava mais a essa camada profunda da história, que se alojava também na base das mentalidades, do que à sucessão das mudanças e dos eventos, como Abdicação, Regência, Maioridade, Revoluções provinciais, que me parecem ser mais outras "tabuletas", como as do romance Esaú e Jacó, do que eventos indicativos de mudanças efetivas. Isto, principalmente, por se darem apenas no plano das elites e por ficarem de fora dos acontecimentos os escravos e o povo mais pobre, metaforizados nos romances de Lúcia Miguel Pereira como os negros, presentes, mas sempre à margem da ação.

Em nenhum outro escrito Machado procurou com tanta concentração essa visão da totalidade da vida social. Aí estão representadas todas as camadas sociais do país: a senhorial dominante e a sua forte constituição hierárquica, os traços de caráter e as deformidades psicológicas de seus membros, um mundo regido pelos mortos, pelos retratos na parede da biblioteca ou da sala de visitas, como em Cabra-Cega; a dos homens livres subordinados cumprindo as suas funções específicas e restritas, cada

7. Id., p. 45 . 
um no seu devido lugar, para não serem tidos por arrivistas ou, pior, "rebeldes"; e a dos negros escravos, afastada, podendo só ser observada à distância, como o fazem o padre-narrador e dona Antônia, na cena em que espiam sobranceiros a conversa de Lalau com o negro sineiro e os dois moleques. O que está ausente nesse mundo fechado é a força do capital comercial e financeiro, que seria a ameaça e o fator de corrupção do mundo tradicionalista. Machado deixa-o de fora talvez para poder analisar as suas vísceras, o seu funcionamento interno de defesa e perpetuação.

Gledson analisa muito bem como Machado criou um tipo de narrativa na primeira pessoa, a do padre narrador, que pôde internar-se na Casa e revelar todos os seus meandros, a sua convivência elegante e as práticas secretas. Como o foco incide sobre a camada senhorial, o que mostra são as suas relações internas próprias, sua procura por ilhar-se e limitar ao mínimo os contatos externos com as demais. Essa determinação cria a falsa impressão de que cada uma tinha vida própria e autônoma, embora todas fossem terrivelmente dependentes e não seriam nada do que eram sem as outras. Nem mesmo os escravos, pois, sem os senhores, não seriam também escravos. Se compreendermos bem as relações vividas pelas diferentes personagens nesse pequeno mundo, saberemos muito das dominantes no país e da mentalidade de seus membros.

O título é um tanto irônico, Casa Velha: de fato é uma casa patriarcal de fins do século XVIII, mas que ainda nos anos da ação da história, 1838 e 1839, depois da Independência e do Primeiro Reinado, estava ainda muito viva. A ironia é que continuava atual também quando de sua escrita por Machado, fosse antes ou depois de Brás Cubas, como se precisasse de algo maior do que a força do capital comercial e financeiro e do "moderno" urbano para transformá-la. Um pequeno traço de sua fachada, que nos passa despercebido por nos ser muito familiar, é significativo bastante para ilustrar a força de sua permanência e pode simbolizar o verdadeiro tema da história da casa velha: a mudança da fachada e dos exteriores, que não abandona nunca os valores que forjaram as concepções interiores de seus membros, ou seja, as camadas profundas que organizam e orientam as suas ações. Esses homens são portadores de uma mentalidade discriminatória, moldada por séculos de escravismo, que, por um lado, segmenta e segrega os homens e, por outro, desvirtua o impulso que poderia levá-los a sua superação, o da atração amorosa. Se o patriarca da casa velha pôde usar deste impulso para se aproveitar da mãe de Lalau para a própria satisfação sexual, o seu filho não pôde segui-lo para unir-se à filha de sua amante para o casamento comum. 
A casa, cujo lugar e direção não é preciso dizer, tinha entre o povo o nome de Casa Velha, e era-o realmente: datava dos fins do outro século. Era uma edificação sólida e vasta, gosto severo, nua de adornos. Eu, desde criança, conhecia-lhe a parte exterior, a grande varanda da frente, os dous portões enormes, um especial às pessoas da família e às visitas, o outro destinado ao serviço, às cargas que iam e vinham, às seges, ao gado que saía a pastar. Além dessas duas entradas, havia, do lado oposto, onde ficava a capela, um caminho que dava acesso às pessoas da vizinhança, que ali iam ouvir missa aos domingos, ou rezar a ladainha aos sábados. ${ }^{8}$

O que mudou das grandes casas, em relação às empetecadas dos atuais bairros nobres brasileiros, talvez tenha sido apenas a perda da severidade e a ausência de adornos. Porém, o que foi colocado no centro da descrição da casa pelo autor, a parte excessiva e desnecessária, os "dous portões enormes", um social, para a família e as visitas, e outro de serviço, para os escravos, os animais e as cargas, não só continuaram e se expandiram, como foram reproduzidos até nos elevadores dos prédios de apartamentos não tão grandes assim da classe média brasileira.

As poucas coisas que não eram velhas na Casa, além de Lalau, a heroína, eram os livros de Voltaire e Rousseau da biblioteca e, talvez, também o padre narrador, que "os conhecia, não integralmente, mas no principal que eles deixaram". ${ }^{9} \mathrm{O}$ conhecimento deles pelo padre era um pouco mais do que um verniz modernizante, incidia na sua ação, mas não impediu que ele se surpreendesse, assim como o leitor, com a decisão firme e radical de Lalau pelo trabalho: ${ }^{10}$ a de não voltar para a casa velha, casar-se com o "Vitorino, o filho do cocheiro", e de não querer uma solução acomodatícia. O contrário do também surpreendente final de Cabra-Cega.

8. Assis, Machado de. Obra completa, vol. I. Rio de Janeiro: José Aguilar, 1974, p. 999.

9. Id., p. 2003.

10. O que corresponde muito ao discurso do revolucionário de 1848 e amigo de Machado, Charles Ribeyrolles, no Brasil pitoresco, escrito por volta de 1858 e de cuja primeira tradução para o português Machado de Assis participou: "Brasileiros, não sois nem botocudos, nem puris, nem portugueses. Sois da filiação humana, tendes avós como nós todos. Homens e povos, não há mais sobre a terra nem velhos, nem moços, nem grandes, nem pequenos. Só há trabalhadores”. E, pouco mais adiante: “É o trabalho que produz os povos. Não sereis, por acaso, responsáveis, como privilegiados da criação, se deixardes por cultivar o mais belo jardim do universo, quando a terra mais áspera do Norte se abre e fertiliza à mão do homem?”. Ribeyrolles, Charles. Brasil pitoresco, vol. 1. São Paulo: Livraria Martins, 1941, pp. 15 e 16. 


\section{NAS ONDAS DA NEGATIVIDADE DO TEMPO}

Se alguém espera ler Cabra-Cega como um grande romance, pode desistir, não é, tem muitos problemas, tanto de concepção como de execução, e a participação da intenção crítica na sua elaboração não está isenta de responsabilidade. As grandes qualidades de Lúcia na crítica literária não se repetem aqui, infelizmente, nem neste que me parece ser o melhor de seus romances. ${ }^{11}$ Porém, o livro fica muito interessante se o lermos a partir de Casa Velha, do aproveitamento crítico que a autora deve ter feito desse outro livro, para a realização daquele; o contraste comparativo entre um e outro acho que poderá nos trazer bons resultados para a compreensão de ambos, do que só terei condições de fazer aqui um esboço.

Muitos elementos que encontramos na composição do livro de Machado também veremos no de Lúcia; ela os retoma num outro tempo e num outro contexto, e com muita consciência do que faz. O que me parece o mais importante é o fato de ela o realizar a partir de uma perspectiva histórica distinta, embora com intenção crítica semelhante: se bem lidos, é fácil notar a distância crítica dos autores no tocante às relações estabelecidas nas duas casas - sem a preocupação que teve Gilberto Freyre, de realçar os traços de cultura próprios da casa-grande, que lhe permitiram abrandar os termos mais rudes da convivência, como os vemos em Casa-Grande \& Senzala. Se, como falei, o objeto de Machado na sua novela ou romance era a permanência, a resistência do velho ao novo, da Casa Velha à ação do tempo, o objeto de Lúcia era o oposto, a casa velha já era vista como uma excrescência num mundo de bangalôs e apartamentos e candidata ao posto de ruína. Lá, o que tínhamos era a resistência ao tempo; aqui, agora, é a forte ação dissolvente do tempo. Em Casa Velha essa força do tempo poderia estar na emergência dos interesses e dos valores ligados às atividades comerciais e financeiras e seus agentes, mas que, praticamente e por razões já aventadas acima, não se faziam presentes. Creio que seja por isso que a ação decidida de Lalau, diferentemente da astuciosa ou "simulada" Capitu, pareça um ato com boa dose de heroísmo, apesar de um tanto inglório, pois o que vence não é o amor, mas o valor pessoal,

11. Luís Bueno faz uma avaliação muito positiva de seus três primeiros romances. No que ele tem toda a razão, quando os aprecia no contexto literário dos anos 30, como contribuições que enriqueceram e ampliaram em muito a visão do romance nesse período. Vistos de hoje, porém, já fica mais difícil reconhecerlhes esse valor; porém, fica como uma fonte documental relevante para o estudo da condição da mulher e da família brasileira na época, como nota Patrícia da Silva Cardoso, no posfácio que escreveu à sua Ficção reunida. Cf.: Bueno, Luís. Uma história do romance de 3o. São Paulo: Edusp; Editora Unicamp, 2006.

Teresa revista de Literatura Brasileira [16]; São Paulo, 2015 • 213 
apoiado em princípios éticos de busca de independência e autonomia, num mundo que deixava pouca margem para isso. Em Cabra-Cega, o ácido que corrói a tradição - além da sua intransigência e conflitos internos que a deixam cheia de trincas - é o dos costumes modernos, trazidos principalmente pela emergência de uma classe média que se pautava mais pela moda e pelo hedonismo do que por princípios morais ou religiosos. Essa camada nova que vinha não tinha nada de elevado, ela se consumia na cotidianidade mais vazia. Entretanto, como em Casa Velha, Lúcia isola uma família tradicional na casa grande de uma velha chácara afastada do centro do Rio, na Gávea, para observar ali a vivência de seu processo ruinoso. Só que, ao contrário do padre narrador de Machado, que era alguém vindo de fora, agora tudo é apreciado por alguém de dentro, Ângela, uma das filhas da família, já não tão extensa como a de Casa Velha. A narrativa é feita na terceira pessoa, mas colada à protagonista e muito próxima de sua visão das coisas. Esse tipo de narrador era moderno e importante, porque ele podia tanto apreciar os fatos com mais objetividade do que o seria pela própria protagonista, como também o movimento do que se passava em seu interior, as suas reações subjetivas a tudo o que acontecia. Lúcia, muito versada na literatura sua contemporânea, principalmente a francesa, a inglesa e a norte-americana, sabia bem que era esse o seu principal objeto de observação. Para mim, a perda maior na passagem de uma narrativa à outra é a da dimensão alegórico-simbólica ou a possibilidade de sua generalidade: se em Casa Velha podemos ver numa escala reduzida o universo mental e cultural das relações sociais dominantes no Brasil, em Cabra-Cega só enxergamos o destino de uma família tradicional, que pode simbolizá-la genericamente no país, mas a sociedade como um todo está muito longe de estar aí representada. Isto não quer dizer que houve por parte da autora só uma perda de visão, ocorreu também uma mudança de enfoque. Se Machado priorizou em seu livro a apreciação das relações internas da Casa vista por alguém de fora, Lúcia priorizou a visão de alguém de dentro, que vivia e avaliava principalmente as relações externas de seus membros. Lá o foco era centrípeto, aqui é centrífugo. A Casa já não pode mais ser pensada como um mundo fechado e autárquico, como talvez já não pudesse também em 1839, ano em que Machado situou a ação de sua história. A principal ameaça que ela vivia, a do capital comercial e da vida urbana da corte, como já falamos, ficou quase inteiramente de fora, o que reduz em muito a dimensão do conflito e faz a narrativa se parecer mais com uma novela ou crônica familiar do que com um romance.

Apesar do nome da heroína, Ângela - ela tem mesmo algo de angélico, tanto nos sentimentos como na aparência externa bela, loira, de olhos azuis, como os do bisavô e da mãe, sulista de origem alemã —, ela, literalmente, tem uma atração forte pela lama e se deleita em chafurdar nos lugares pantanosos da chácara. E é o que de fato acontece no 
final do romance, só que agora metaforicamente, quando acompanha um desconhecido qualquer que a acode na rua, se embriaga com ele e aceita o convite para irem ao apartamento dele. A cena tem em vista provocar no leitor muito mais o sentimento de rendição do que de libertação. $\mathrm{O}$ que parecia anunciar no começo um fundo psicanalítico, uma espécie de "nostalgia da lama", das pulsões inconscientes, termina como uma fraqueza herdada de família: como os demais membros, ela se deixar levar também pelo sopro do vento luxurioso do tempo. Não há aqui nada do heroísmo de Lalau, há antes o contrário, uma rendição total aos novos costumes e ao tempo, o que, de certa forma, vinha fazendo já quase toda a família: a mãe era conhecida pelos casos que tinha fora do casamento; a irmã, Sílvia, que justificava também o nome, era um tanto selvagem, "anormal", tinha relações lesbianas; o irmão, Jorge, frequentava à noite o quarto de uma criada mulata, engravidou-a e a abandonou, e esta acabou afogando o filho, foi presa e se matou; a tia Regina era louca e vivia reclusa e escondida num chalé no fundo da chácara, com uma outra negra não muito mais saudável do que ela, por ter sido internada, como veremos mais abaixo, num hospício, porque contrariou as práticas delituosas e incestuosas da casa grande. Como podemos ver, Ângela não fez mais do que ceder às forças dissolventes do tempo ou ao jogo do destino, Cabra-Cega: aquela brincadeira infantil de vedar os olhos e tentar pegar o próximo a quem transferir a cegueira.

Quase todos, menos o pai e a avó; são estes que resistem e cultuam o passado, deixam-se reger pelos mortos e tentam manter a casa em pé. O pai teria um pouco a função acomodatícia do padre-narrador de Casa Velha. Equivaleria a ele, tem também algo de ilustrado e moderno, é um matemático, acadêmico, tido como sábio, com um discurso liberal a favor da liberdade e igualdade das pessoas e dos sexos. Mas, quando surgem as oportunidades de concretizá-lo, recua à sua velha tradição patriarcal. Por exemplo, espanca a filha, Sílvia, quando sabe de sua amizade estreita com Ernestina, "que tem o vício de namorar moças, como se fosse homem"; ${ }^{12}$ ou como reage, quando, através de uma carta anônima, que Ângela descobre depois ter sido escrita pela própria avó, é informado de um dos casos da mulher, e, devido a isso, a renega.

No entanto, é a avó a personagem com maior identidade com a outra de Casa Velha, d. Antônia, o esteio da casa e da tradição. Logo no início temos um quadro que lembra a descrição da biblioteca da novela de Machado:

12. Pereira, Lúcia Miguel. Ficção reunida. Organização de Patrícia da Silva Cardoso. Curitiba: Editora da UFPR, p. 444. 
De súbito, sente que não quer o destino da avó, não quer envelhecer na casa onde nasceu: Anita [uma amiga de Ângela] tem razão, parece um museu. Um museu onde os mortos - os mortos e a semimorta: a louca - abafam os vivos, uns com a sua perfeição, a outra com a sua desgraça. Ocorre-lhe de repente a lembrança da mais grave travessura da sua primeira infância: o bombardeio com caroços de cambucá, do retrato do avô general, tão feio, tão solene, tão duro na sua farda cheia de dourados, contrastando com a negrura dos bigodes e com o tom escuro da face morena. Já era nascida quando morreu, mas não se lembra dele. Sem dúvida porque lhe valeu o maior castigo que sofreu, ainda hoje lhe inspira aversão. Não entende como a sua avó, tão branda, tão bonita, se casou com um homem tão antipático. Simpático deve ter sido o bisavô, que se habituou a chamar de vovô Conselheiro, cujo retrato defronta, na sala de visitas, o do genro militar. Dizem que herdou dele o azul dos olhos, o louro dos cabelos, a alvura da pele. E também o gênio impulsivo, e o amor pela chácara. Quando a vê, sempre que alguém a magoa, refugiar-se entre as árvores, a avó exclama: "É tal qual meu pai!"”³

Os retratos dos mortos - aqui desdobrados no do marido general da avó, com ares autoritários, e no de seu pai, meigo e polido, um pouco como o Conselheiro Aires fazem com que eles continuem presentes e governando os vivos. A avó é descrita como branda e bonita, e é de fato a amiga e confidente da neta; porém, quando contrariada, renasce nela a senhora de escravos. Numa ocasião, na qual a neta lhe contou que teve contato com Ritinha, a negra que convivia com a filha louca, foi deste modo que reagiu:

Agora é que se torna severa a expressão da avó, severa como nunca a viu. A testa se franze, a boca faz-se imperativa.

"Quem lhe permitiu conversar com Ritinha? Você tem disso proibição formal".

"Ninguém deixou, fui eu quem quis. Já estive duas vezes no chalé, falei com Ritinha e vi tia Regina. Ritinha disse que eu era o retrato dela".

"Ritinha é louca, ainda mais do que Regina. Fique sabendo que isso não se repetirá nunca mais; você será severamente castigada se insistir".

"Se Ritinha também é maluca, como é que toma conta de tia Regina?"

"Para Regina, ela é muito boa, mas tem mania de perseguição. Julga-nos a todos culpados da doença de Regina. Por gratidão é que a admitimos aqui, porque a mãe dela criou Regina e seu pai. Os médicos acham que seria prejudicial para ambas separá-las. Mas irá

13. Id., p. 372. 
para o hospício se eu souber que falou mais com você. Peste! Megera! Hei de ensiná-la a ser tagarela! E você a ser desobediente!".

As frases saem sem ordem, as palavras se atropelam. Ângela não reconhece a avó naquela velha furiosa, de fisionomia decomposta e gestos violentos. Quando ela a segura pelos ombros, e lhe indaga desabridamente por que, como, quando ousara ir ao chalé, tem a impressão de ver na sua frente a louca. ${ }^{14}$

Era essa a "santa", como era considerada pelas irmãs de caridade e pela própria neta: "Vovó é uma santa". Só que, depois, descobriu uma cláusula (e as razões) que condicionava os seus donativos a serem aplicados apenas "em benefício dos asilados de cor branca que melhores aptidões revelarem". ${ }^{15}$ As razões são explicadas com a descoberta de que foi uma das duas figuras altivas dos retratos da sala de visita, o avô general, que se aproveitara da irmã louca da mulher, da tia Regina, engravidara-a e dera fim a seu filho.

Desesperada, Ritinha tentou matar vovô. Foi um escândalo. Vovó soube de tudo, evidentemente. E mancomunou-se com o marido para internar Ritinha no hospício, como louca furiosa. Quando voltou - só saiu porque um médico parece ter suspeitado da verdade - a criança já tinha nascido. Por uma preta velha, que ajudou vovó no parto, soube que era um menino, e fora posto na Roda, no Asilo dos Expostos.

Quando Ângela sabe disso, ameaça uma ação com algum "heroísmo", resiste e se recusa a compactuar com os crimes da família. Ensaia negá-la e denunciar tudo à polícia. Mas, ao tentar fazê-lo, perde também a confiança na instituição e nos agentes da ordem, no caso, no delegado. Como se não visse outra saída, com muita facilidade aceita a rendição e se nivela aos demais, entra no jogo, como disse acima. A conclusão que fica ao leitor é a de que o novo não era muito melhor do que o velho, e quanto à vida, por não sabermos bem no que consistia nem onde estava, talvez o melhor fosse mesmo ficar de fora dela. A crítica aos costumes da casa-grande da família tradicional é complementada com a crítica aos novos costumes do tempo da vida burguesa. De modo que na passagem de uma para outra só havia perdas, sem dizer que não tinha

14. Id., p. 419
15. Id., p. 436. 
mais também nenhum retrato na parede a ser cultuado. ${ }^{16} \mathrm{O}$ jogo da cabra-cega talvez servisse para ilustrar essa situação, da pessoa de olhos vendados sem saber para onde ir, nem para frente nem para trás, e ficar girando em círculos como um bobo, para o riso dos demais. Esse seria o resultado elaborado pela visão da autora, paralisada entre um apego conservador e uma aspiração modernizante, que não deve ser confundido com o sentido do processo histórico.

A pergunta que fica é até que ponto a androginia, a reunião da crítica à criação, contribuiu ou não para a boa realização do romance. Não teria sido preferível um registro mais isento dos dramas da decadência familiar no embate com a história e a sua experiência disso? A autora tinha muito claros todos os desarranjos a serem denunciados: a hipocrisia necessária de todos, os crimes ocultos de cada um, a loucura escondida dos olhos do outro, os vícios e as tendências hereditárias etc. Assim como conhecia todos os procedimentos narrativos da literatura moderna, basta lermos a sua crítica e vermos como era frequentadora assídua de Virgínia Woolf, Joyce, Kafka, Gide, Proust. Porém, outros romances brasileiros da época, de meu ponto de vista, fizeram isso melhor; veja-se, por exemplo, o livro de Helena Morley, Minha vida de menina, ou, posteriormente, o romance de Lúcio Cardoso, Crônica da casa assassinada. E o que Lúcia apresenta é também uma visão crítica um tanto superficial e esquemática dos costumes modernos do tempo. O que já vinha sendo feito também por outros, mas sem tanto parti pris, como os livros de Marques Rebelo, A estrela sobe, e, depois, O espelho partido. O que pode significar que a visão crítica dos eventos e da literatura, decisiva e fundante da melhor ironia, nem sempre é suficiente e substitui a sensibilidade e a sinceridade (como a adesão maior à verdade da realidade externa do que à da vontade subjetiva, que pode muitas vezes ser contrariada pelos fatos), fundamentais para o registro artístico e literário. Por isso teria também aqui, segundo a norma, o homem traído a mulher?

Luiz Roncari é professor de literatura brasileira da Universidade de São Paulo e autor de Buriti do Brasil e da Grécia: patriarcalismo e dionisismo no sertão de Guimarães Rosa (Editora 34, 2013), entre outros livros.

16. V. como Luís Bueno discute a mesma questão nos seus primeiros romances. Uma história do romance de 30. Op. cit., p. 313. 